\title{
Roles of Sulfhydryl Compounds in the Gastric Mucosal Protection of the Herb Drugs Composing Oren-Gedoku-To (a Traditional Herbal Medicine)
}

\author{
Hideki Takase, Osamu Inoue, Yuji Saito, Eizaburou Yumioka and Akira Suzuki \\ Kampo Research Laboratories. Kanebo. Ltd., Tomobuchi-cho 1-5-90. Miyakojima-ku. Osaka 534, Japan \\ Received June 9, 1990 Accepted May 1,1991
}

\begin{abstract}
We investigated the involvement of sulfhydryl compounds in the cytoprotective effect of each component herb drug composing Oren-gedoku-to (OGT) against ethanol-induced gastric lesions and potential difference (PD) reduction in comparison with that of OGT in rats. Pretreatment with $\mathrm{N}$-ethylmaleimide (NEM) significantly blocked the cytoprotective effects of OGT, Coptidis rhizoma and Phellodendri cortex, but did not block the cytoprotective effects of Gardeniae fructus and Scutellariae radix. The inhibitory effects of OGT, Coptidis rhizoma and Phellodendri cortex against the PD reduction disappeared in the presence of NEM or diethyldithiocarbamate (DDC), whereas NEM or DDC had little or no effect with Gardeniae fructus and Scutellariae radix. These results suggest that the gastric mucosal protection of Coptidis rhizoma and Phellodendri cortex may be ascribed to the reinforcement of mucosal barrier resistance through endogenous sulfhydryl compounds and DDC-sensitive compounds, but those of Gardeniae fructus and Scutellariae radix may be independent of NEM- or DDC-sensitive compounds.
\end{abstract}

We have already found that Oren-gedoku-to (OGT) exhibited mucosal protection against ethanol injury, and its effect was decreased by pretreatment with $\mathrm{N}$-cthylmalcimide (NEM), an endogenous sulfhydryl blocker (1). These findings suggested that OGT, acting on the factors of defense mechanism including sulfhydryl compounds, exerted mucosal protective effects (1). Therefore, it is important to examine which of the four herb drugs composing OGT are involved in the mucosal protection through sulfhydryl compounds and exactly how they act to confer this protection.

Gastric potential difference (PD) sensitively reflects the integrity of the gastric mucosal barrier $(1-8)$. Since the PD values decline as a result of barricr disruption owing to damage in the gastric mucosa, it has been confirmed that there is a relationship between the grade of gastric mucosal damage and the PD values $(1,5-8)$. In the present study, in order to determine which of four herb drugs composing OGT show mucosal protection by reinforcement of the gastric mucosal barrier through sulfhydryl compounds, we investigated the effects of the herb drugs composing OGT against ethanol-induced gastric lesions and ethanol-induced PD reduction in the absence and presence of NEM, respectively, in rats.

Diethyldithiocarbamate (DDC) $(9,10)$, a strong copper chelating agent, has been known to induce gastric mucosal damage by decreasing the factors of mucosal defense mechanisms such as mucosal blood flow and PD $(11,12)$. In addition, it has been reported that DDC at higher dose $(1000 \mathrm{mg} / \mathrm{kg})$ pro- 
duced a fall in the activity of supcroxide dismutase (SOD) in the gastric mucosa (13). In our preliminary experiment, we have found that DDC per se had no effect on the values of the PD under urethane anesthesia and that the inhibitory effect of OGT against ethanolinduced $\mathrm{PD}$ reduction was reversed by pretreatment with DDC. Based on these findings, we compared the effects of the herb drugs composing OGT against ethanol-induced PD reduction in the presence of DDC with those in the presence of NEM and explored the possibility that the DDC-sensitive compounds in addition to sulfhydryl compounds may be responsible for the maintenance of the integrity of the gastric mucosal barrier by each component herb drug. It has been reported that DDC induced marked decreases in the gastric acid output, one of the aggressive factors as well as decreases in gastro-duodenal mucosal blood flow and transmucosal PD, two of the defensive factors against gastric mucosa (13). Thus, it is impossible to adequately investigate the effects of DDC on the formation of the gastric lesions, since DDC has the ability to either aggravate or improve gastric lesions.

The doses of Coptidis rhizoma, Scutellariae radix, Phellodendri cortex and Gardeniae fructus used were based on previous findings (14). Namely, in the case of each component herb drug, the higher doses $(100$ and $250 \mathrm{mg} / \mathrm{kg}$ ) were applied in order to clearly evaluate the effects of NEM and those of DDC on the gastric mucosal protection of the drugs, respectively, although each dose used was comparatively higher than that contained in the doses of OGT. In addition, OGT and glutathione were employed as control drugs.

\section{MATERIALS AND METHODS}

\section{Animals and drugs}

Male Wistar rats (ST, substrain from Shizuoka Lab. Co., Ltd.), weighing $170-200 \mathrm{~g}$, were used. The animals were fasted overnight, but allowed free access to water up to the beginning of the experiment. OGT (yield: $17.5 \%$ ) was extracted with hot water from
Coptidis rhizoma, Scutellariae radix, Phellodendri cortex and Gardeniae fructus combined in the ratio of $1.5: 3: 1.5: 2$, and the aqueous extract was concentrated and spraydried in a hot air stream as described previously (14). The component herb drugs were extracted with hot water, and the aqueous extract was concentrated and freeze-dried. The yields of the extracts of the component herb drugs were previously reported (14). The following drugs were used: ethanol (Wako), reduced glutathione (Wako), N-ethylmaleimide (NEM) (Wako), and diethyldithiocarbamate (DDC) (Sigma). OGT, component herb drugs, glutathione, NEM and DDC were dissolved in saline and each given in a volume of $5 \mathrm{ml} / \mathrm{kg}$ of body weight.

\section{Ethanol-induced gastric lesions}

Gastric mucosal lesions were produced according to the method of Robert et al. (15). The rats received a subcutaneous injection of cither vehicle or NEM $(10 \mathrm{mg} / \mathrm{kg})$ in vehicle (saline) $1 \mathrm{hr}$ before ethanol treatment. Then, $30 \mathrm{~min}$ prior to oral administration of $1 \mathrm{ml}$ of $99.5 \%$ ethanol, OGT $(100 \mathrm{mg} / \mathrm{kg})$, Coptidis rhizoma $(100 \mathrm{mg} / \mathrm{kg})$, Scuiellariae radix $(250$ $\mathrm{mg} / \mathrm{kg})$, Phellodendri cortex $(100 \mathrm{mg} / \mathrm{kg})$, Gardeniae fructus $(250 \mathrm{mg} / \mathrm{kg})$, glutathione $(250 \mathrm{mg} / \mathrm{kg}$ ), or vehicle was orally given to the individual rats that had been pretreated with vehicle or NEM. One hr after ethanol treatment, the animals were sacrificed. The stomach was removed and inflated by injecting 10 $\mathrm{ml}$ of $1 \%$ formalin to the gastric lumen for 10 min. Subsequently, the stomach was incised along the greater curvature and examined for lesions. The length $(\mathrm{mm})$ of each lesion was measured under a dissecting microscope $(\times 10)$ with a square grid, and the sum per stomach was used as the lesion index.

\section{Gastric potential difference $(P D)$}

The experimental procedure was essentially the same as that described by Nagashima et al. (5). Under anesthesia with urethane (1.25 $\mathrm{g} / \mathrm{kg}$, i.p.), the trachea of rats were cannulated. The abdomen was opened and the stom- 
ach exposed. The esophagus was ligated without disturbing the vagus nerves. One catheter filled with $3 \%$ agar in saturated $\mathrm{KCl}$ was inserted into the stomach through an incision in the duodenum and served as the intragastric electrode. A temporary gastric fistula was prepared using a polyethylene tube in the forestomach. This fistula which led to a three-way tap was used for intragastric instillation and for removal of gastric contents. A second catheter filled with $3 \%$ agar and saturated $\mathrm{KCl}$ was inserted into the peritoneal cavity and served as the indifferent electrode. The intragastric and intraperitoneal electrodes were both placed in separate beakers containing saturated $\mathrm{KCl}$ solution in which balanced $\mathrm{Ag}$ $\mathrm{AgCl}$ clectrodes were positioned. The whole interior of the stomach was gently rinsed with warm saline 3-4times, and then $4 \mathrm{ml}$ of saline was instilled into the stomach. The changes in PD were continuously monitored using a recorder connected to the millivoltometer. PD recordings were taken at 3 -min intervals. The gastric PD measurements were done at the corpus portion where the tip of the detecting electrode was placed. Each drug was intragastrically administered prior to treatment with $40 \%$ ethanol. NEM $(10 \mathrm{mg} / \mathrm{kg})$ and DDC $(250 \mathrm{mg} / \mathrm{kg})$ werc administered subcutaneously $0.5 \mathrm{hr}$ before drug treatment, respectively.

\section{Statistics}

Data are expressed as the mean $\pm \mathrm{S}$.E. The data were analyzed by one-way analysis of variance and the differences between treatment groups compared by the Dunnett's $t$-test or Duncan's multiple range test, and values of $\mathrm{P}<0.05$ were regarded as significant.

\section{RESULTS}

Effects of OGT, Coptidis rhizoma, Scutellariae radix, Phellodendri cortex, Gardeniae fructus and glutathione on ethanol-induced gastric lesions in the absence or presence of NEM

The degree of protection afforded by OGT $(100 \mathrm{mg} / \mathrm{kg})$ was $61.2 \%$ in the absence of
NEM; it was significantly higher when compared with that $(6.8 \%)$ obtained in the presence of NEM (Fig. 1). Glutathione (250) $\mathrm{mg} / \mathrm{kg}$ ) exhibited a significant protection in the absence of NEM; the degree of protection $(64.9 \%)$ was significantly higher as compared with that $(7.1 \%)$ obtained in the presence of NEM (Fig. 1). Administration of the salineCoptidis rhizoma $(100 \mathrm{mg} / \mathrm{kg})$ combination resulted in $76.7 \%$ inhibition of ethanol-induced gastric lesions as compared to the vehiclevehicle-treated group (Fig. 2). However, the combination of administration of NEM (10 $\mathrm{mg} / \mathrm{kg}$ ) and Coptidis rhizoma $(100 \mathrm{mg} / \mathrm{kg})$ resulted in a significant decrease of inhibitory ratio of gastric lesions as compared to the group treated with vehicle and Coptidis rhizoma $(24.6 \%$ versus $76.7 \%)$. Administration of the vehicle-Phellodendri cortex $(100 \mathrm{mg} / \mathrm{kg})$ combination resulted in $67.8 \%$ inhibition of ethanol-induced gastric lesions as compared to the vehicle-vehicle-treatcd group (Fig. 2). However, the combination of administration of NEM $(10 \mathrm{mg} / \mathrm{kg})$ and Phellodendri cortex $(100 \mathrm{mg} / \mathrm{kg})$ resulted in a significant decrease of the inhibitory ratio of gastric lesions as
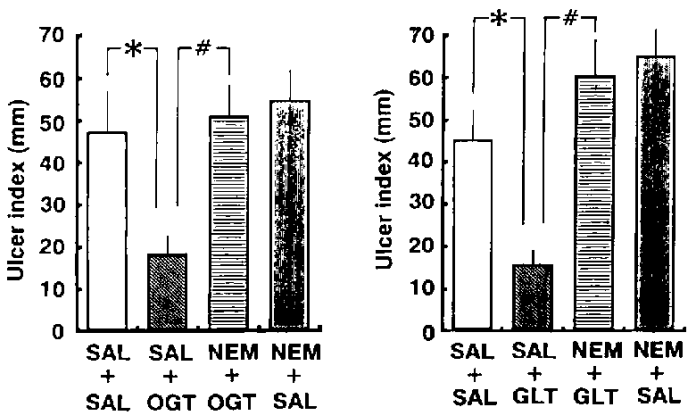

Fig. 1. Influence of NEM $(10 \mathrm{mg} / \mathrm{kg})$ on the cytoprotective effect of Oren-gedoku-to (OGT, $100 \mathrm{mg} / \mathrm{kg}$ ) or glutathione (GLT, $250 \mathrm{mg} / \mathrm{kg}$ ) against ethanol-induced gastric lesions. The rats received a subcutaneous injection of either vehicle or NEM in vehicle (saline). Thirty minutes later, the rats pretreated with vehicle or NEM were orally administrered OGT, GLT, or vehicle. Heights of bars represent the means and vertical lines, the $\mathrm{S}$. E. of seven observations. ${ }^{*} \mathrm{P}<0.05$, compared to saline-saline-treated rats. ${ }^{\#} \mathrm{P}<0.05$. compared to saline-OGT- or saline-GLT-treated rats. 

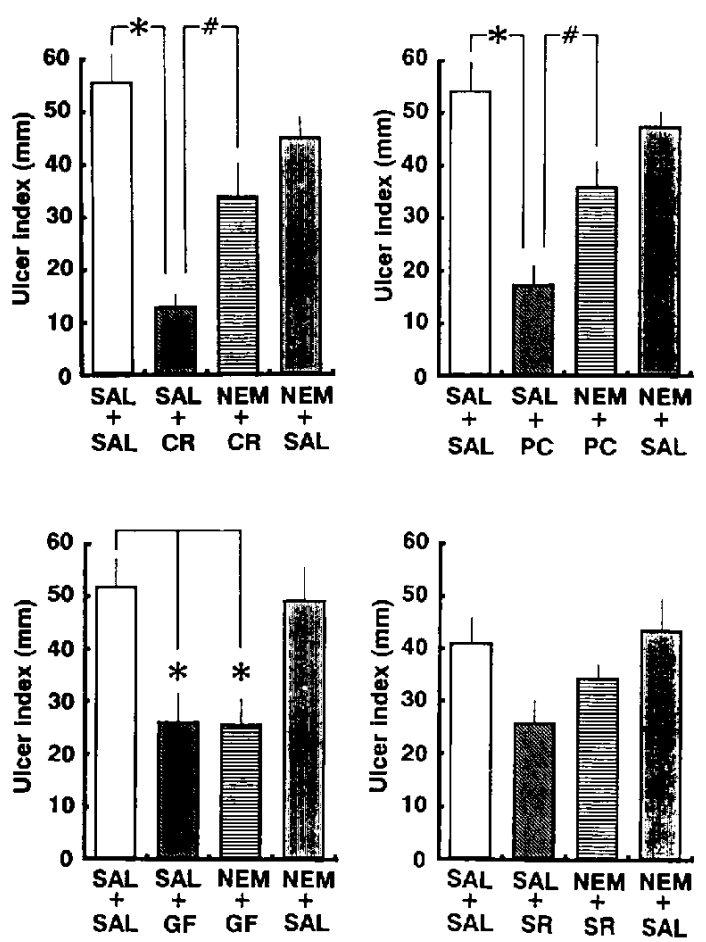

Fig. 2. Influence of NEM $(10 \mathrm{mg} / \mathrm{kg})$ on the cyloprotective effect of Coptidis rhizoma (CR, $100 \mathrm{mg} / \mathrm{kg}$ ), Scutellariae radix (SR, $250 \mathrm{mg} / \mathrm{kg}$ ), Phellodendri cortex (PC, $100 \mathrm{mg} / \mathrm{kg}$ ) or Gardeniae fructus (GF, 250) $\mathrm{mg} / \mathrm{kg}$ ) against ethanol-induced gastric lesions. The rats received a subcutaneous injection of either vehicle or NEM in vchicle (saline). Thirty minutes later, the rats pretreated with vehicle or NEM were orally administered CR, SR, PC, GF or vehicle. Heights of the bars represent the means and vertical lines, the S.E. of ten observations. ${ }^{*} \mathrm{P}<0.05$, compared to satinesaline-treated rats. ${ }^{*} \mathrm{P}<0.05$, compared to saline-CRor saline-PC-treated rats.

compared to the group treated with vehicle and Phellodendri cortex $(24.1 \%$ versus $67.8 \%)$. Gardeniae fructus $(250 \mathrm{mg} / \mathrm{kg})$ showed a significant protective action in the absence of NEM; the degree of protection $(49.7 \%)$ was almost equal to that $(48.1 \%)$ obtained in the pesence of NEM (Fig. 2). Scutellariae radix $(250 \mathrm{mg} / \mathrm{kg})$ inhibited the lesion formation by $37.0 \%$ and $21.3 \%$ in the abscnce and presence of NEM, respectively (Fig. 2). However, it was not significant.
Effects of OGT, Coptidis rhizoma, Scutellariae radix, Phellodendri cortex, Gardeniae fructus and glutathione on ethanol-induced $P D$ reduction by pretreatment with $N E M$ and $D D C$

As shown in Table 1, OGT (100 and 250 $\mathrm{mg} / \mathrm{kg})$, Coptidis rhizoma $(100$ and 250 $\mathrm{mg} / \mathrm{kg}$ ), Scutellariae radix $(250 \mathrm{mg} / \mathrm{kg})$, Phellodendri cortex $(100$ and $250 \mathrm{mg} / \mathrm{kg})$, Gardeniae fructus (100 and $250 \mathrm{mg} / \mathrm{kg}$ ) and glutathione $(250 \mathrm{mg} / \mathrm{kg})$ significantly prevented the $P D$ reduction induced by cthanol, whereas Scutellariae radix $(100 \mathrm{mg} / \mathrm{kg})$ failed to prevent it. After intragastric instillation of $2 \mathrm{ml}$ of $40 \%$ cthanol, the control rats without and with NEM (10 mg/kg, s.c.) or DDC (250 $\mathrm{mg} / \mathrm{kg}$, s.c.) pretreatment caused a $\mathrm{PD}$ reduction of $15.9+1.4 \mathrm{mV}(\mathrm{N}=8)$ and $16.1 \pm 0.9$ $\mathrm{mV}(\mathrm{N}=8)$ or $17.6 \pm 1.4 \mathrm{mV}(\mathrm{N}=8)$, respectively. These values were not statistically significant, indicating that neither NEM nor DDC at the doses tested affected $40 \%$ ethanol-induced $P D$ reduction.

The inhibitory effect of OGT (100 and 250) $\mathrm{mg} / \mathrm{kg}$ ) on ethanol-induced $\mathrm{PD}$ reduction was decreased by pretreatment with NEM and DDC, respectively. Pretreatment with NEM and DDC lowered the inhibitory effect of Coptidis rhizoma (100 and $250 \mathrm{mg} / \mathrm{kg}$ ) against the PD reduction induced by ethanol, respectively. The inhibitory effect of Scutellariae radix $(250 \mathrm{mg} / \mathrm{kg})$ on ethanol-induced $\mathrm{PD}$ reduction was unaffected even in the presence of NEM and DDC, respectively. Pretreatment with NEM and DDC attenuated the inhibitory effect of Phellodendri cortex $(100$ and 250 $\mathrm{mg} / \mathrm{kg}$ ) against ethanol-induced $\mathrm{PD}$ reduction, respectively. Gardeniae fructus (100 and 250 $\mathrm{mg} / \mathrm{kg}$ ) showed a significant inhibitory effect against ethanol-induced $P D$ reduction even in the presence of NEM and DDC, respectively. The inhibitory effect of glutathione (250 $\mathrm{mg} / \mathrm{kg}$ ) on the $\mathrm{PD}$ reduction was attenuated by pretrcatment with NEM and DDC, respectively. 
Table 1. Effects of Oren-gedoku-to (OGT). Coptidis rhizoma. Scutllariae radix. Phellodendri cortex. Gardeniae fractus and glutathione on ethanol-induced PD reduction in the absence or presence of N-ethylmaleimide (NEM) and diethyldithiocarbamate (DDC) in ancsthetized rats

\begin{tabular}{|c|c|c|c|c|c|c|}
\hline \multirow{2}{*}{ Ireatment } & $\begin{array}{c}\text { Dose } \\
\mathrm{mg} / \mathrm{kg}\end{array}$ & $\mathrm{N}$ & Nonce & $\begin{array}{l}\text { Pretreatment } \\
\text { NEM }\end{array}$ & DDC & \multirow[b]{2}{*}{$(\mathrm{mV})$} \\
\hline & & & & & & \\
\hline $\begin{array}{l}\text { Control } \\
\text { (Saline) }\end{array}$ & - & 8 & $\begin{array}{c}15.911 .4 \\
(100 \%)\end{array}$ & $\begin{array}{c}16.1+(0.9 \\
(100 \%)\end{array}$ & $\begin{array}{r}17.6+1.4 \\
(100 \%)\end{array}$ & \\
\hline $\mathrm{OGT}$ & 100 & 6 & $\begin{array}{c}8.0 \pm\left[.3^{*}\right. \\
(50.3)\end{array}$ & $\begin{array}{c}15.3 \pm 2.5^{\#} \\
(95.0)\end{array}$ & $\begin{array}{c}15.7 \pm 1.4^{\#} \\
(86.9)\end{array}$ & \\
\hline \multirow{3}{*}{$\begin{array}{l}\text { Coplidis } \\
\text { rhizoma }\end{array}$} & 250 & 7 & $\begin{array}{c}7.0 \pm 1.2^{*} \\
(44.11)\end{array}$ & $\begin{array}{c}12.1 \pm 1.5^{\#} \\
(75.2)\end{array}$ & $\begin{array}{c}12.6 \pm 1.4^{\#} \\
(71.6)\end{array}$ & \\
\hline & $100)$ & 7 & $\begin{array}{c}10.3 \pm 0.7^{*} \\
(64.6)\end{array}$ & $\begin{array}{c}15.4 \pm 1.7^{ \pm} \\
(95.7)\end{array}$ & $\begin{array}{c}16.1) \pm 2.1 \\
(90.9)\end{array}$ & \\
\hline & 250 & 7 & $\begin{array}{c}7.6 \pm 0 . x^{*} \\
(47.5)\end{array}$ & $\begin{array}{c}12.6 \pm 1.5^{\#} \\
(78.3)\end{array}$ & $\begin{array}{c}12.9 \pm 1.8^{\#} \\
(73.3)\end{array}$ & \\
\hline \multirow[t]{2}{*}{$\begin{array}{l}\text { Scunellariae } \\
\text { radix }\end{array}$} & $100)$ & 6 & $\begin{array}{c}14.0+1.5 \\
(88.1)\end{array}$ & N.T. & N.T. & \\
\hline & 250 & 6 & $\begin{array}{c}9.2=0.9^{*} \\
(57.9)\end{array}$ & $\begin{array}{c}8.5 \pm 1.1^{*} \\
(52.8)\end{array}$ & $\begin{array}{c}9.2 \pm 1.2^{*} \\
(52.3)\end{array}$ & \\
\hline \multirow[t]{2}{*}{$\begin{array}{l}\text { Phellodendri } \\
\text { cortex }\end{array}$} & 100 & 7 & $\begin{array}{l}8.1 \pm 1.2^{*} \\
(50.9)\end{array}$ & $\begin{array}{c}13.0 \pm 1.2^{\#} \\
(80.7)\end{array}$ & $\begin{array}{c}16.0 \pm 2.0 \\
(90.9)\end{array}$ & \\
\hline & 250 & 6 & $\begin{array}{c}5.7 \pm 1.3^{*} \\
(35.8)\end{array}$ & $\begin{array}{c}10.5+1.2^{\ddagger} \\
(65.2)\end{array}$ & $\begin{array}{c}11.3+1.6^{*} \\
(64.2)\end{array}$ & \\
\hline \multirow[t]{2}{*}{$\begin{array}{l}\text { Gardeniae } \\
\text { frucias }\end{array}$} & 1000 & 6 & $\begin{array}{c}9.2 \pm 1.4^{*} \\
(57.9)\end{array}$ & $\begin{array}{c}10.2 \pm 1.8^{*} \\
(63.4)\end{array}$ & $\begin{array}{c}10.5 \pm 1.5^{*} \\
(59.7)\end{array}$ & \\
\hline & 250 & 6 & $\begin{array}{c}7.2+0.5^{*} \\
(45.3)\end{array}$ & $\begin{array}{c}9.7 \pm 1.0^{*} \\
(60.2)\end{array}$ & $\begin{array}{c}9.0 \pm 1.2^{*} \\
(51.1)\end{array}$ & \\
\hline Glutathione & 250 & 7 & $\begin{array}{c}9.6 \pm 0.8^{*} \\
(6(1) 4)\end{array}$ & $\begin{array}{c}15.3+1.7^{\#} \\
(95.0)\end{array}$ & $\begin{array}{c}13.6+1.4^{\ddagger} \\
(77.3)\end{array}$ & \\
\hline
\end{tabular}

Each value represents the mean $\pm \mathrm{S}$.E., the number of animals in each experiment being $6-x$. Each drug was intragastrically administered prior to treatment with $40 \%$ ethanol. NEM (10 mg/ $\mathrm{kg}$, s.c.) and DDC (250 mg/ $\mathrm{kg}$, s.c.) was given $30 \mathrm{~min}$ before administration of ethanol, respectively. ${ }^{*} \mathrm{P}<0.05$. statistically significant difference as compared to each control group under the same conditions (Dunnett's t-test). \#P< 0.15. statistically significant difference as compared to each drug alone at the same dose without pretreatment (Duncan's maltiple range test). N.T.: Not Tested.

\section{DISCUSSION}

The present results have also shown that the inhibitory effect of OGT, as well as that of glutathione, against ethanol-induced gastric lesions and ethanol-induced $\mathrm{PD}$ reduction disappeared by pretreatment with NEM in accordance with the previously reported results (1). These results support the previous assumption that the cytoprotective effect of OGT may be ascribed to maintenance of the mucosal barrier integrity by its interaction with sulfhydryl compounds (1).

Pretreatment with NEM significantly attenuated the protective effects of Coptidis rhizoma $(100 \mathrm{mg} / \mathrm{kg})$ and Phellodendri cortex $(100)$ $\mathrm{mg} / \mathrm{kg}$ ) against ethanol-induced gastric lesions and the inhibitory effects of these two herb drugs on ethanol-induced $P D$ reduction at the same dose, respectively. These results suggest that Coptidis rhizoma and Phellodendri cortex exert cytoprotective effect by the maintenance 
of the gastric mucosal barrier mediated through sulfhydryl compounds. The degree of protection ( $49.7 \%$ ) by Gardeniae fructus alone at $250 \mathrm{mg} / \mathrm{kg}$ against ethanol-induced gastric lesions was almost equal to that $(48.1 \%)$ obtained in the presence of NEM, and the prevention was significant. In addition, at the same dose, Gardeniae fructus displayed significant inhibition of the $\mathrm{PD}$ reduction even by pretreatment with NEM. that is to say, the protective effect of Gardeniae fructus does not seem to be associated with sulfhydryl compounds. Scutellariae radix exhibited no significant protective effect against ethanol-induced gastric lesions at the dose tested $(250 \mathrm{mg} / \mathrm{kg})$. However, Scutellariae radix at the dose of 250 $\mathrm{mg} / \mathrm{kg}$ a showed protection of the gastric mucosal barrier, and this protection was not affected by NEM. Therefore, the protection by Scutellariae radix seems to be indifferent to sulfhydryl compounds. In addition, since the inhibitory effect of Gardeniae fructus on ethanol-induced PD reduction was superior to that of Scutellariae radix, it is likely that the difference between the former and the latter is due to the difference in the potency of the protection on the gastric mucosal barrier. Furthermore, both Gardeniae fructus and Scutellariae radix prevented ethanol-induced gastric lesions at higher doses than that required to inhibit ethanol-induced PD reduction, thereby suggesting that Gardeniae fructus and Scutellariae radix might exert their protective effect on the gastric mucosal barrier by a local action. Thus, the above-described findings revealed that Coptidis rhizoma and Phellodendri cortex, qualitatively like OGT. possessed cytoprotective activitics by the reinforcement of the gastric mucosal barricr through sulfhydryl compounds, and Gardeniae fructus and Scutellariae radix protected the gastric mucosal barrier by a different mechanism.

It has been reported that NEM (16) and DDC (17) altered and inactivated the conformation and the function of sulfhydryl compounds and copper containing enzyme, respectively. Furthermore. DDC has been found to alter the function of glutathione in the cell $(18-20)$. The present results suggested that OGT, similar to glutathione. showed mucosal protective effect through DDC-sensitive compounds in addition to NEM-sensitive sulfhydryl compounds.

In the present study, DDC as well as NEM antagonized the inhibitory effects of Coptidis rhizoma and Phellodendri cortex against ethanol-induced PD reduction. These findings suggest that the conformational and functional maintenance of NEM- or DDC-sensitive sulfhydryl compounds may play an essential role in the maintenance of the mucosal barrier integrity afforded by Coptidis rhizoma and Phellodendri cortex. On the other hand, both DDC and NEM failed to antagonize the inhibitory activities of Gardeniae fructus and Scutellariat radix against ethanol-induced PD reduction. Hence, it is presumed that the inhibitory effects of Gardeniae fructus and Scutellariae radix against the $\mathrm{PD}$ reduction are irrelevant to DDC-sensitive compounds as well as NEM-sensitive sulfhydryl compounds.

Thus, the changes of the PD values in the DDC-pretreatment groups corresponded to those obtained in the NEM-pretreatment groups. Namely, the above-described findings suggest that NEM-sensitive sulfhydryl compounds correlate to DDC-sensitive copper containing compounds. For example, a copper containing sulfhydryl compound such as SOD, which is assumed 10 play an important role in the gastric mucosal defense mechanisms (21, 22), may be involved in the maintenance of the gastric mucosal barricr by Coptidis rhizoma and Phellodendri cortex.

As mentioned above, it is worthwhile noting that Coptidis rhizoma and Phellodendri cortex. similar to OG', exhibit gastric mucosal protection by the reinforcement of the gastric mucosal barrier through endogenous sulfhydryl compounds and DDC-sensitive compounds. On the other hand, Gardeniae fructus and Scutellariae radix exhibited the protection of the gastric mucosal barricr by a mechanism independent of NEM- or DDC-sensitive compounds. 


\section{REFERENCES}

1 Takase, H., Imanishi, K., Miura, $O$. and Yumioka, E.: A possible mechanism for the gastric mucosal protection by Oren-gedoku-to (OGT). a traditional herbal medicine. Japan. J. Pharmacol. 51, 17-23 (1989)

2 Davenport, H.W.. Warner, H.A. and Code. C.F.: Functional significance of gastric mucosal barrier to sodium. Gastroenterology 47, $142-152$ (1964)

3 Geall, M.G.. Phillips, S.F. and Summerskill. W.H.J.: Profile of gastric potential difference in man: effects of aspirin, alcohol, bile and endogenous acid. Gastroenterology 58, 437-443 (1970)

4 Takeuchi, K., Nobuhara, Y. and Okabe, S.: Changes in transmucosal potential difference and luminal $\mathrm{pH}$ in anesthetized rat stomach after exposure to ethanol. Japan. J. Pharmacol. 33, 910-914 (1983)

5 Nagashima, R., Hoshino, H., Hinohara, Y., Sakai, K., Hata, S. and Nakano, H.: Effect of sucralfate on ethanol-induced gastric mucosal damage in the rat. Scand. J. Gastroenterol. 18. Supp. 83 , $17-20(1983)$

6 Ivey, K.J.: Gastric mucosal barrier. Gastroenterology 61. 247-257 (1971)

7 Baskin, W.N. Ivey, K.J., Krausse, W. J., Jefferey, G.E. and Gemmell, R.T.: Aspirin-induced ultrastructural changes in human gastric mucosa correlation with potential difference. Ann. Intern. Med. 85, 299-303 (1976)

8 Pendleton, R.G. and Stavorski, J.M.: Effects of indomethacin, aspirin and related compounds on the transgastric potential difference in cats. Arch. Int. Pharmacodyn. Ther. 263, 146-154 (1983)

9 Heikkila, R.E., Cabbat, F.S. and Cohen, G.: In vivo inhibition of superoxide dismutase in mice by diethyldithiocarbamate. J. Biol. Chem. 251, $2182-$ 2185 (1976)

10 Frank, I.., Wood, D.L. and Roberts, R.J.: Effect of diethyldithiocarbamate on oxygen toxicity and lung enzymc activity in immature and adult rats. Biochem. Pharmacol. 27, 251 - 254 (1977)

11 Ashida. Y.. Murakami, M., Mizuno, M., Hozu, S. Saita, H. and Miyake, T.: Elfect of diethyldithiocabamic acid on gastric mucosal potential difference and blood flow. Japan. J. Gastrenterol. 83, 1554 (1986) (in Japanese)

12 Ogino, K., Oka, S., Mazuda, S., Yoshimura, S.,
Sakaida, I., Okazaki, Y. and Takemoto. T.: Studies of superoxide dismutase in rat gastric mucosal injury. Japan. J. Gastroenterol. 84, 205-209 (1987) (Abs. in English)

13 Takamasu, M., Fuse, Y., Kawamoto, K., Komada, T. and Ohishi. T.: Possible mechanisms of diethyldithiocarbamate-induced gastro-duodenal mucosal damage in rats. Scand. J. Gastroenterol. 24. Supp. 162, $112-115$ (1989)

14 Takase, H., Imanishi, K., Miura, O., Yumioka, E. and Watanabe, H.: Features of the anti-ulcer effects of Oren-gedoku-to (a traditional Chinese medicine) and its component herb drug. Japan. J. Pharmacol. 49, 301-308 (1989)

15 Robert, A., Nezamis, J.E., Lancaster, C. and Hancher, A.J.: Cytoprotection by prostaglandin in rats: Prevention of gastric necrosis produced by alcohol, $\mathrm{HCl}, \mathrm{NaOH}$, hypertonic $\mathrm{NaCl}$ and thermal injury. Gastroenterology 77, 433-443 (1979)

16 Takeuchi, K., Okada, M., Niida, H. and Okabe, $S$.: Role of sulfhydryls in mucosal injury caused by ethanol: relation to microvascular permeability, gastric motility and cytoprotection. J. Pharmacol. Exp. Ther. 248. 836-841 (1988)

17 Szelenyi, I. and Brune, K.: Possible role of oxygen free radicals in ethanol-induced gastric mucosal damage in rats. Dig. Dis. Sci. 33,865-871 (1988)

I8 Denke, S. and Fanburg, B.L.: Involvement of glutathione enzyme in $\mathrm{O}_{2}$ tolerence development by diethyldithiocarbamate. Biochem. Pharmacol. 29. $1367-1373(1980)$

19 Kelner, M.J. and Alexander, N.M.: Inhibition of erythrocyte superoxide dismutase by diethyldithiocarbamate also results in oxyhemoglobincatalyzed glutathione depletion and methemoglobin production. J. Biol. Chem. 261, 1636-1641 (1980)

20 Sinet, P.M., Garber, P. and Jerome, H.: $\mathbf{H}_{2} \mathrm{O}_{2}$ production, modification of the glutathione status and methemoglobin formation in red blood cells exposed to dicthyldithiocarbamate in vitro. Biochem. Pharmacol. 31, 521-525 (1982)

21 Fridovich, I.: Superoxide radical and superoxide dismutase. Acc. Chem. Res. 5. 321 - 326 (1972)

22 McCord, J.M., Kecle, B.B. and Fridovich, I.: An enzyme-based theory of obligate anaerobiosis: The physiological function of superoxide dismutase. Proc. Natl. Acad. Sci. 68, 1024-1027 (1971) 